\title{
An Analysis of Employees' Satisfaction in Distribution Enterprises Based on PLS SEM-A Case Study of A Corporation
}

\author{
Wei Liu ${ }^{1, a,{ }^{*}}$, Jing Chen ${ }^{2, b}$ and Junxiong You ${ }^{3, c}$ \\ ${ }^{1}$ Xiamen University Tan kah kee college modern logistics and supply chain innovation research \\ center, Zhangzhou, 363105, China \\ ${ }^{2}$ Xiamen University Tan kah kee college, Zhangzhou 363105, China \\ ${ }^{3}$ Xiamen University Tan kah kee, Zhangzhou 363105, China \\ aliuwei568@xujc.com, bSCL14050@stu.xujc.com, cjsyou@xujc.com \\ ${ }^{*}$ Corresponding author
}

Keywords: Circulation Enterprise, PLS, SEM, Employee Satisfaction.

Abstract. High-quality human resources bring more benefits and rapid development to enterprises in the crucial period of development of distribution companies. Therefore, how to improve employee satisfaction to attract talents is of great significance to the development of the company. However, the satisfaction of employees in circulation enterprises is affected by many factors. The degree of employee satisfaction and loyalty is relatively low, which seriously restricts the development of circulation enterprises. Based on Maslow's Demand Theory and Fairness Theory, this paper uses A circulation enterprise as an example to establish a partial least-squares structural equation model. Using SPSS software and smart PLS3 software as an analysis tool to test the hypothesis, the constructed model has better stability. Sex, the working has a greater direct effect on the working condition, satisfaction and incentives, the working condition has a greater direct effect on employee satisfaction and motivations, career prospects have a greater direct effect on the working and motivations, and career prospects There is a greater indirect effect on the working condition, employee loyalty and satisfaction. Therefore, circulation companies should systematically establish a system for assessing employee satisfaction, regularly evaluate employee satisfaction, and take appropriate measures to increase employee satisfaction.

\section{Introduction}

The circulation industry has become a hub for convergence of production and consumption because it can realize the spatial movement of objects, and circulation efficiency has become a part of production efficiency. According to statistics from the National Bureau of Statistics of China, total social logistics in China reached 252.8 trillion RMB in 2017, an increase of 23.1 trillion RMB over 2016, providing more than 30 million jobs, further expanding the industry scale and becoming an indispensable pillar of national economic development. one. As one of the main bodies of economic activities, circulation enterprises are not only related to their own competitiveness, but also directly related to the strength of the country's overall strength. Therefore, the development of distribution companies is of great significance to the development of the country.

However, the development of distribution companies is not optimistic. On the one hand, the growth potential of the circulation industry has attracted companies to seize market share and circulation channels. Various e-commerce festivals have emerged. The market appears to be prosperous, but it lacks effective constraints and guidance. On the other hand, fierce competition for the market has inevitably triggered a price war. Companies have to pass on the negative consequences of the price war to employees. This results in low pay and high load for employees in the circulation industry. The employment environment is harsh and personnel flow. The rate is high. Therefore, how to guide the circulation enterprises to carry out healthy competition and improve the satisfaction of employees to reduce the flow rate of the employees in the circulation enterprises has become a problem that must be solved for the continuous development of the circulation industry. 
Because companies are increasingly aware of the importance of employee satisfaction, many scholars have conducted in-depth research[1-2], but the study of domestic employee satisfaction began late, coupled with differences in national conditions and many other factors, domestic The research methods of employee satisfaction, especially those with more satisfaction in the circulation industry, remain at the qualitatively-oriented stage. The lack of a systematic system that is universally recognized is an important reason that the academic community still needs to discuss in depth.

Partial Least Squares Structural Equation Model (PLS SEM) has been widely used in enterprise operations [3-4]. This method has no rigid requirements for the distribution of data and does not require multivariate normal distribution of data. It is completely based on the original data modeling. , and it will not result in an invalid model that does not meet the premise. At the same time, many models have a large demand for sample size, and it is generally considered that a sample size of less than 200 is more suitable for adopting a partial least-squares structural equation model. Therefore, in combination with the actual situation of the surveyed enterprises, the structural equation model was established by collecting the influencing factors of employees' satisfaction in circulation enterprises, and the dimensions were scored using the partial least squares calculation method. From this, it was concluded that each factor influences the satisfaction of the employees of circulation enterprises. Based on the strengths and weaknesses of this system, the system develops improvement methods, and factors with large influence and low scores are taken as the main improvement direction. In accordance with the sequence of improvement strategies, gradually improving employee satisfaction can help the company form a certain period of sustained employee satisfaction. The evaluation mechanism continuously summarizes the rules in the evaluation and reinforces employee loyalty through the conduction of satisfaction.

\section{Theoretical Basis and Research Hypothesis}

\subsection{The theoretical basis of employee satisfaction}

The concept of employee satisfaction has been proposed so far. The Hawthorne Effect, Maslow's Demand Theory, and Fairness Theory have dominated the definition, evaluation and promotion of employee satisfaction. The theoretical foundation of the main basis for the satisfaction of employees in circulation enterprises is Maslow's needs theory and fairness theory.

\subsubsection{Maslow's Demand Theory}

Maslow's book Human Incentives divides human needs from low to high into 1 physiological needs: including food, water, and other physical needs. 2 Security needs: physical satisfaction and physical and mental security. 3 social needs: including love, belonging, acceptance, friendship needs. 4 The need for respect: including self-respect, sense of achievement, and degree of social acceptance. 5 Self-actualization needs: Beyond the recognition of others and society and focus on whether their abilities are brought into play, and whether individuals can be expected.

Li Mengxi and Chen Zenan[5] discovered in the study that due to differences in the national conditions and customs of Asian countries and Western countries, Maslow's hierarchy of needs theory does not fully apply to China's national conditions. The effect of this measure on incentives is due to Different, so the specific incentives will depend on the individual. In the adoption of incentive measures, attention should be paid to incentives such as appreciation, promotion opportunities, compensation, remuneration systems, and working conditions. Some of them cannot be used alone, and they need to work synergistically with other incentives. For the members of the organization, the organization should pay attention to and tap the real needs of employees and strive to meet their needs. Therefore, Maslow's hierarchy of needs theory inspires companies to understand the true aspirations of their employees, accurately analyze their needs, and pay attention to the balance and coordination of demands at all levels in order to effectively increase employee satisfaction. 


\subsubsection{Fairness Theory}

The core of the fairness theory is to compare the employees to compare their input-output ratios to compare horizontally with others; or to use the current input-output ratio to compare with a certain vertical phase in the past as a basis for judging whether the pay distribution is fair. Only when employees feel that their current input-output ratio is greater than or equal to the past and others will be satisfied.

It can be seen that the fairness is easily affected by personal cognitive level, social standards and other factors, and is entirely determined by the individual's subjective judgment. The employee cares about the absolute value of the salary, but is satisfied by the relative value. Wang Zhigang and Zhou Yonggang et al.[6] research based on the perspective of fairness theory show that due to the difference in gender and the department in which individuals are employed, employees' perceived fairness differences result in significant differences in satisfaction. Therefore, while constructing a fair and reasonable remuneration system, enterprises must also take measures to create a fair and reasonable atmosphere. For example, they should guide employees not to blindly compete, and establish that there is no absolute fairness.

\subsection{Factors affecting employee satisfaction}

According to the different research perspectives, this article summarizes the factors affecting employee satisfaction into three categories: the first category is the job-related attribute dimension, the second category is the employee personal characteristic dimension, and the third category is the multi-dimensional. The research content of this paper is based on job-related attribute dimensions. Therefore, this article will conduct empirical research on relevant factors of job attribute dimensions and analyze satisfaction and loyalty.

Seashore et al.[7] classified the factors related to employee satisfaction into two categories: antecedent variables and outcome variables. The former dependent variables of employee satisfaction are environmental factors and personal attribute factors. The employee satisfaction variable variables are demographic variables, organizational response variables, and social response variables. According to Seashore's research framework, this paper divides the influencing factors of employee satisfaction in circulation companies into two categories: antecedent factors and consequence factors. Among them, the antecedent factors are used to evaluate the degree of satisfaction that affects employees' satisfaction in all dimensions; the consequential factors are the possible attitudes and behaviors of employees under the influence of their own satisfaction levels. Select employee satisfaction variables as shown in Table 1 .

Table 1.Employee satisfaction variable table.

\begin{tabular}{|c|c|c|}
\hline $\begin{array}{l}\text { Latent } \\
\text { variable }\end{array}$ & Explicit variable & $\begin{array}{l}\text { Signed variable } \\
\text { symbol }\end{array}$ \\
\hline \multirow[t]{4}{*}{$\begin{array}{l}\text { Career } \\
\text { prospects }\end{array}$} & Career promotion space for employees & QJ1 \\
\hline & training opportunity & QJ2 \\
\hline & Rising space & QJ3 \\
\hline & The degree of work stability & QJ4 \\
\hline \multirow[t]{9}{*}{ Working } & Interest in work & BS1 \\
\hline & Work on time constraints & $\mathrm{BS} 2$ \\
\hline & The degree of work & BS3 \\
\hline & Work pressure situation & BS4 \\
\hline & The working is difficult and challenging & BS5 \\
\hline & Overtime & BS6 \\
\hline & $\begin{array}{l}\text { Comparison of expectations before entry into service and } \\
\text { actual expectations }\end{array}$ & BS7 \\
\hline & $\begin{array}{l}\text { Based on previous work experience, anticipation of current } \\
\text { work }\end{array}$ & BS8 \\
\hline & $\begin{array}{l}\text { According to the employees' understanding of similar work } \\
\text { outside the company, their expectations for the current work }\end{array}$ & BS9 \\
\hline
\end{tabular}


Table 1 to be continued

\begin{tabular}{llc}
\hline $\begin{array}{l}\text { Working } \\
\text { condition }\end{array}$ & Office environment & HJ1 \\
\hline & Leisure facilities & HJ2 \\
\hline & Management system (system implementation strength) & HJ3 \\
\hline & Bosses treat the subordinates equally & HJ4 \\
\hline & Good relationship with colleagues & HJ5 \\
\hline & Close teamwork & HJ6 \\
\hline Motivation & Values & JL1 \\
\hline & Recognition of colleagues and leaders & JL3 \\
\hline & Remuneration & JL4 \\
\hline Employee & After the contract expires, do you want to stay in the & JL5 \\
\hline & company? & ZC1 \\
\hline loyalty & Business sense of belonging & ZC2 \\
\hline & Whether you are willing to cooperate with the company & ZC3 \\
\hline Satisfaction & character & GT1 \\
\hline & Personal creativity of employees & JL2 \\
\hline & Overall satisfaction with the current job & BS10 \\
\hline
\end{tabular}

\subsection{1 pre-causal factors model and assumptions}

Vroom[8] research shows that the main factors affecting employee satisfaction are: the company itself, promotion space, nature of work, leaders, compensation and benefits, working condition, and colleagues. Smith and Hullin[9] research showed that the main factors affecting employee satisfaction are: the working salary, promotion, direct leadership, and five colleagues are all positively related to employee satisfaction. Locker[10] research shows that the working, compensation, personal promotion, recognition, working condition, welfare, self, managers, colleagues, company partners, etc. are closely linked to employee satisfaction. Ganesan[11] pointed out that employee satisfaction will be affected by: employee perception, effective communication, authorization, motivation, work relationships, job participation, employee participation, compensation, work-life balance, organizational commitment, and corporate culture and atmosphere. After fully analyzing related theories, Liu Caijuan[12] determined the influencing factors of employee satisfaction as: the ratio of input and salary at work, space for rising positions, corporate humanistic care, employee career planning, and interest in the working. Wang Wenjun[13] divided the satisfaction of employees in Sichuan Province into four dimensions:working, working atmosphere, company system, and organizational environment. The research of Zhao Liang[14] shows that the working, wages and salaries, working condition, and the relationship between leaders and colleagues have a positive effect on employee satisfaction. The research of Xu Qin[15] pointed out that there is a significant positive correlation between the five dimensions of job environment satisfaction, job group satisfaction, organization and management satisfaction, job satisfaction, personal satisfaction, and employee satisfaction. Explain that the five categories of indicators jointly affect employee satisfaction, and any one of the factors that make the employee's satisfaction decline may lead to a decline in the satisfaction of other factors, thereby reducing the overall level of employee satisfaction.

In summary, this article believes that the five factors of career prospects, working, working condition, motivation, and satisfaction are the pre-causal factors that constitute employees' satisfaction in circulation enterprises. Based on the above research, the following hypotheses are proposed:

Hypothesis 1: There is a positive correlation between the working and the working condition. The better the employees feel about the working, the better the working condition will feel.

Hypothesis 2: There is a positive correlation between working and employee satisfaction. The better the employee feels the working, the higher the employee satisfaction.

Hypothesis 3: There is a positive correlation between working condition and employee satisfaction. The more satisfied employees are with the working condition, the higher the employee satisfaction level. 
Hypothesis 4: There is a positive correlation between career prospects and the working. The better the career prospects, the better the employees think the working.

Hypothesis 5: There is a positive correlation between career prospects and employee satisfaction. The better the career prospect, the higher the employee satisfaction.

Hypothesis 6: There is a positive correlation between career prospects and motivations. The better the career prospects, the greater the motivation to employees.

\subsubsection{Post-causal factor models and assumptions}

By measuring the degree of employee satisfaction, it can be concluded that each employee in the company causes a difference in satisfaction due to their own characteristics, level of needs, and other reasons. The company is committed to minimizing such differences and meeting the needs of employees at different levels as much as possible. The purpose is to receive feedback from employees. Gao Fuxia[16] proposed that employee loyalty can not only reduce the cost of recruitment and training, but also help the company's Long-term development. And employee loyalty can be divided into two types of attitudes and behavioral loyalty and is similar to satisfaction. It is a kind of emotional tendency that cannot be directly measured. Jacob and Mikkel[17] found empirically that the influence coefficient of employee satisfaction on employee loyalty is 0.5 , indicating that employee satisfaction is increased by $1 \%$ and loyalty is increased by $0.5 \%$. Wang Hongmei[ 18$]$ believes that environmental factors, corporate factors, and personal factors not only affect employee satisfaction but also employee loyalty, and that the compensation and benefits in corporate factors have a positive effect on employee satisfaction and loyalty. Liu Dexiu, Qin Yuanhao, and Xu Zi[19] believe that there is no significant positive effect of attitude loyalty on behavioral loyalty. Attitude is one of the influencing factors of behavior and cannot determine behavior. Zhang Xiaomei[20] found that employee job satisfaction has a higher positive effect on loyalty.

In summary, the three indicators set up are whether they are willing to continue signing with the company, whether they are willing to advance and retreat with the company, and the sense of belonging to the company. Based on the above research results, the following assumptions are made:

Hypothesis 7: Employee satisfaction has a significant positive impact on loyalty. The higher the employee satisfaction, the higher the employee loyalty.

Hypothesis 8: Motivations have a significant positive impact on loyalty, the greater the motivation, the higher the loyalty.

\section{Research design}

\subsection{Questionnaire distribution}

The questionnaires were distributed to employees of the A medium and small-sized circulation enterprises in Xiamen City, an important node in the Belt and Road, from October 2017 to November 2017. A total of 143 questionnaires were distributed, 101 valid questionnaires were recovered, and the total questionnaires were valid. It is $80.8 \%$. The sample size meets the requirement of a small sample, non-normal distribution of partial least-squares structural equation modeling. In the effective questionnaire, the proportion of males is higher than that of females, reaching $60.4 \%$. This is because A-trading companies provide third-party logistics services to other companies while logistics is self-operating. The demand of front-line employees is relatively large, so the company Mostly men. A. The average level of employees' working time in circulation enterprises is relatively high. From the distribution of employee positions, managers accounted for $8.9 \%$ of the total; the proportion of ordinary employees was $65.3 \%$, and frontline operators accounted for $12.9 \%$ of the total.

\section{2 data analysis}

The overall characteristics of the descriptive statistics of the data collected in this questionnaire are as follows: Among the 101 questionnaires that are effectively recovered, the employee's gender, education, income, working years at the company, and positions are summarized in Table 2. 
Table 2.Basic statistics of employees.

\begin{tabular}{cccccc}
\hline gender & number & percentage & years of work in the enterprise & number & percentage \\
\hline male & 61 & $60.4 \%$ & above 10 & 16 & $15.8 \%$ \\
\hline female & 40 & $39.6 \%$ & 6-10 years & 20 & $19.8 \%$ \\
\hline education & number & percentage & 3-6years & 24 & $23.8 \%$ \\
\hline below college & 45 & $44.6 \%$ & 1-3years & 11 & $10.9 \%$ \\
\hline college & 23 & $22.8 \%$ & below 1year & 30 & $29.7 \%$ \\
\hline undergraduate & 33 & $32.7 \%$ & nature of the work & number & percentage \\
\hline master's degree & 0 & $0.00 \%$ & support staff & 13 & $12.9 \%$ \\
\hline PhD & 0 & $0.00 \%$ & frontline operators & 13 & $12.9 \%$ \\
\hline age & number & percentage & General staff & 66 & $65.3 \%$ \\
\hline above 50 & 9 & $8.9 \%$ & middle and senior managers & 9 & $8.9 \%$ \\
\hline $46-50$ & 28 & $27.7 \%$ & & & \\
\hline $36-45$ & 13 & $12.9 \%$ & & & \\
\hline $31-35$ & 18 & $17.8 \%$ & & & \\
\hline $26-30$ & 8 & $7.9 \%$ & & & \\
\hline below 25 & 25 & $24.8 \%$ & & & \\
\hline \multicolumn{7}{c}{5} & & & \\
\hline
\end{tabular}

\section{Model Analysis and Hypothesis Testing}

\subsection{Analysis cross-load matrix}

When using the partial least-squares method for path modeling, cross-load coefficient matrix will be generated, because the value of this matrix represents the relationship between explicit variables and latent variables, so it can be used to test whether the selection of explicit variables is reasonable. The value of the diagonal position in the matrix is the load factor for each set of explicit variables and their corresponding latent variables. The values on the other off-diagonal positions are the loads between each set of explicit variables and other latent variables that do not correspond to its coefficient.

The load factor for each explicit variable and its corresponding latent variable on the diagonal must be greater than the load factor between the explicit variables on the non-diagonal position and other latent variables that do not correspond to it. The explicit variable that cannot meet this condition must be greater. The ability to explain latent variables is poor.The use of Smart PLS3 to calculate the cross-load matrix table found that the explicit variables BS3, BS4, BS6, BS9, BS10, HJ5, HJ6, JL1, and JL3 did not satisfy the above conditions and were therefore eliminated. After removing the above variables, the models and tables were adjusted.

In the culling cross-load matrix, it can be concluded that the 21 coefficients located at the diagonal positions are all larger than the corresponding coefficients at other positions and satisfy the conditions. This shows that the remaining 21 indicators of this indicator are reasonable.

\subsection{Reliability analysis}

Use SPSS22.0 software to calculate employee satisfaction. The reliability coefficients of the six scales are all higher than 0.85 , and the total reliability coefficient is 0.956 , which is highly reliable. That is to say, the employee's job satisfaction obtained from this questionnaire is stable.

\subsection{Validity analysis}

The KMO and Barlett sphericity test results show that the KMO is greater than 0.5 and the significance is less than 0.001 , which indicates that the data satisfies the conditions for factor analysis.

When performing factor analysis, it should be noted that the extracted common factors must satisfy the eigenvalues of the extracted common factors that are greater than one, and at the same time, they can reflect the sum of the variance of each indicator at least $65 \%$. 
The eigenvalues of the six common factors that can be extracted from the 21 indicators are all greater than 1 and can reflect the sum of $75.474 \%$ of the variance, so it can be concluded that the questionnaire has a higher structural validity.

\section{An Analysis of Employees' Satisfaction Model in A Corporation}

The remaining 6 latent variables and the corresponding 21 explicit variables are listed in Table 1 for the meaning of the specific indicators. One of the reasons why this paper uses partial least squares to estimate the model is that it can meet the requirements of small sample operations, and the output is standardized. Figure 1 is a road map of the results calculated using Smart PLS3 software.

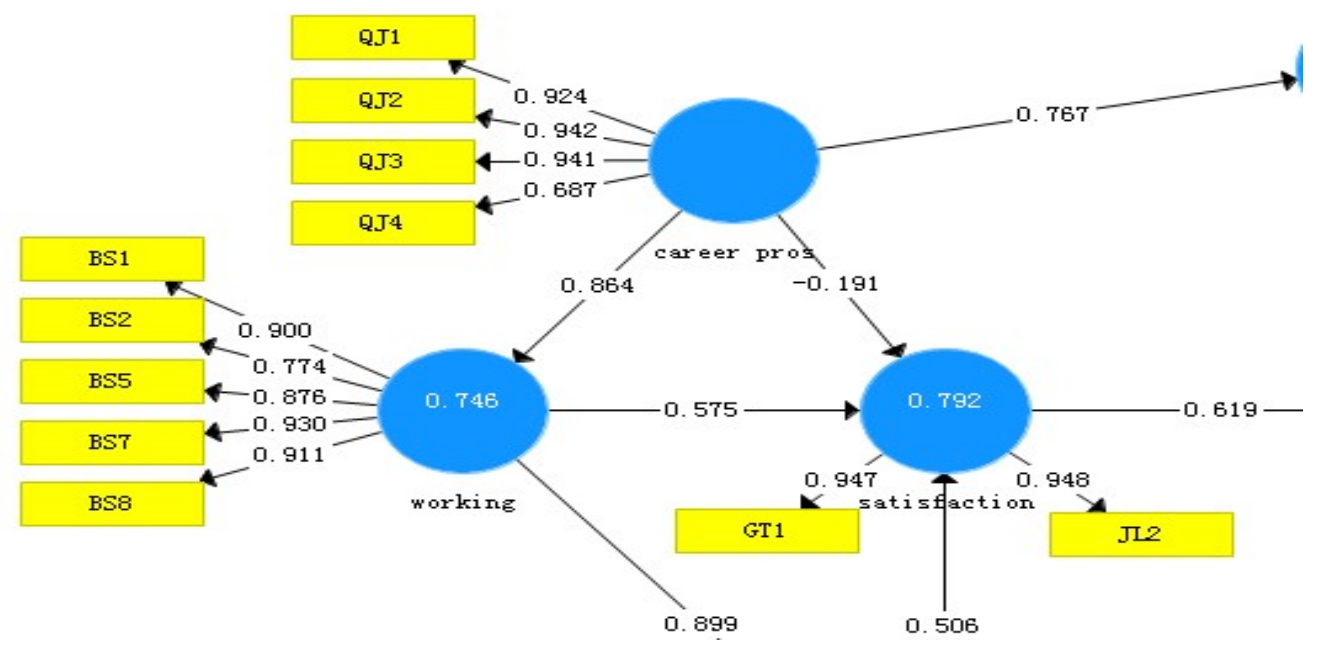

Fig.1. Result of A corporation employee satisfaction model.

\subsection{Effect analysis of the model}

Smart PLS3 is used to calculate total and indirect effects, but direct effects cannot be directly output. Therefore, direct effects need to be calculated using the equation of indirect effect + direct effect $=$ total effect. As shown in Table 3, the first thing to notice in the three effects is the direct effect, and if there is no direct effect between the relationships, the indirect effect is not practical. Secondly, we should pay attention to the total effect. Under the premise of direct effect, the total effect can show the final result of the interaction between factors and have a certain reference value.

Table 3.Total effect.

\begin{tabular}{cccc}
\hline Latent variable path pointing & Indirect effect & direct effect & Total effect \\
\hline working $\rightarrow$ working condition & 0.000 & 0.899 & 0.899 \\
\hline working $\rightarrow$ loyalty & 0.637 & 0.000 & 0.637 \\
\hline working $\rightarrow$ Satisfaction & 0.454 & 0.575 & 1.029 \\
\hline working $\rightarrow$ motivation & 0.000 & 0.797 & 0.797 \\
\hline working condition $\rightarrow$ loyalty & 0.313 & 0.000 & 0.313 \\
\hline working condition $\rightarrow$ Satisfaction & 0.000 & 0.506 & 0.506 \\
\hline working condition $\rightarrow$ motivation & 0.000 & 0.897 & 0.897 \\
\hline Satisfaction $\rightarrow$ loyalty & 0.000 & 0.619 & 0.619 \\
\hline motivation $\rightarrow$ loyalty & 0.000 & 0.321 & 0.321 \\
\hline Career prospects $\rightarrow$ working & 0.000 & 0.864 & 0.864 \\
\hline Career prospects $\rightarrow$ working condition & 0.776 & 0.000 & 0.776 \\
\hline Career prospects $\rightarrow$ loyalty & 0.679 & 0.000 & 0.679 \\
\hline Career prospects $\rightarrow$ Satisfaction & 0.889 & -0.190 & 0.699 \\
\hline Career prospects $\rightarrow$ motivation & 0.000 & 0.767 & 0.767 \\
\hline
\end{tabular}


According to Table 3, the total effect among latent variables, except for the total effect of loyalty on incentives is 0.321 , they are all greater than 0.5 ; there are six pairs above 0.8 , indicating that the interaction between variables is relatively high. Employee satisfaction is affected by the three factors of working, working condition, and career prospects, including both direct and indirect effects. In the path effect of employees' satisfaction in circulation enterprises, the total effect of the working on satisfaction is the greatest, the effect value is 1.029; the total effect of the working condition on satisfaction is 0.506 ; the total effect of career prospect on satisfaction is 0.699 . Therefore, these three factors are the key factors to improve employee satisfaction in A corporation.

Unlike other paths, the direct effect of career prospects on employee satisfaction is -0.190 , and the indirect effect is 0.889 . The direct effect force weakens the overall effect between the two. This paper argues that this shows that career prospects have an important impact on employee satisfaction. The indirect effect of 0.889 is a proof, but the direct effect is a negative effect. This shows that the company has not played a role in the career planning of some employees. When I was promoted against other colleagues, I felt unfair and I was dissatisfied. This made my career prospect negative. The relationship between the remaining variables of the model is as follows:

The four latent variables of working, working condition, satisfaction, and development prospects all have higher total value of loyalty. However, further observations can be found that in addition to the direct effect of satisfaction on loyalty, the influence of other factors on loyalty is indirect. In other words, in fact, only if employees are dissatisfied or dissatisfied will directly result in loyalty and loyalty.

The working has an influence on the working condition, employee loyalty, satisfaction, and motivation, and the total effect value can reach about 0.8 . The work itself has a direct impact on the work environment and the impact of incentives. This shows that the work itself largely determines the work environment and the incentives it brings; the indirect effect of the work itself on employee loyalty is 0.629 . Far greater than the direct effect.

The overall effect of career prospects on work itself, working condition, loyalty, satisfaction, and motivation is positive, and they all fall above and below 0.7 , which is a relatively high level. The career prospects have a direct effect on the working and its motivation. It shows that the career prospects are more attractive to employees. The effect of career prospects on the working condition, loyalty, and satisfaction is dominated by indirect effects. The direct effects are all negative or 0 .

The working condition will affect loyalty, satisfaction, and motivation in varying degrees. The direct effect of the working condition on satisfaction and motivation is the direct effect; the direct effect of satisfaction on loyalty is 0.619 ; Loyalty is affected by a greater degree of satisfaction. The influence of motivation on loyalty is relatively insignificant, with a total effect of only 0.321 , indicating that A corporation currently have less effective incentives for employees.

\section{Conclusion and suggestion}

\subsection{Conclusion}

After a preliminary analysis of the questionnaire data, the cross-load matrix was used to screen the indicators of the visibly variable of the employee satisfaction degree constructed in this paper, and the model was fine-tuned accordingly; finally, the reliability and validity of the adjusted model were analyzed. An empirical study was conducted on the satisfaction model. Firstly, the path coefficient of the model was estimated. In the internal model, the correlation between the latent variables was verified and the hypothesis proposed in this paper. Only the career prospects had an effect on satisfaction. Not significant; Secondly, test the model uniqueness, path coefficient and model effect; Finally, combine the model's indirect effect and total effect to analyze the model's satisfaction index.

\subsection{Suggestion}

According to the above analysis, to improve the employee satisfaction of A corporation, we must first find indicators that are highly relevant to employee satisfaction but dissatisfied with the employees. 
On this basis, we observe whether there are differences in demand among different employee groups and formulate differences. Measures. Therefore, A corporation should systematically establish a system for assessing employee satisfaction, regularly evaluate employee satisfaction, analyze employee needs in a timely manner, and make adjustments based on changes in employee needs. The results of this employee satisfaction evaluation show that the four main points that employees of $A$ corporation need to improve at present are the development of employees' careers, the addition of leisure facilities for amateurs, the increase in salaries, the implementation of flexible welfare systems, and the continuous improvement of employees, satisfaction and loyalty.

\section{Acknowledgement}

This research was financially supported by the Social Science Foundation of Fujian (Grant NO. FJ2016B244).

\section{References}

[1] OLAFSEN A H, ALVARI H, Motivational mechanisms in the relation between job characteristics and employee functioning, Spanish Journal Psychology, 2017, 20

[2] JABEEN F, FRIESEN H L, GHOUDI K, Quality of work life of emirati women and its influence on job satisfaction and turnover intention: evidence from the UAE, Journal of Organizational Change Management, vol.31, pp.352-370, 2018.

[3] PENG D X, LAI F J, Using partial least squares in operations management research: a practical guideline and summary of past research, Journal of Operations Management, vol.30, pp.467-480, 2012.

[4] GROEN B A C, WOUTERS M J F, WILDEROM C P M, Employee participation, performance metrics, and job performance: a survey study based on self-determination theory, Manage Account Research, vol.36, pp.51-66, 2017.

[5] Li mengxi, Chen zelan, The main factors affecting employees' job satisfaction, Enterprise Reform and Management, vol.13, pp.73-74, 2017.

[6] Wang zhigang, Zhou yonggang, Zhao xingjian, Study on the Salary Satisfaction of Research Institute Staff under the Perspective of Fairness Theory, Modern Management Science, vol.9, pp.9-10, 2013.

[7] Seashore, Developing leadership skills for future medical leaders, American journal of Diseases of Children, vol.6, pp.639-642, 1975.

[8] Vroom, V.H, Ego-involvement, job satisfaction and job performance, Personnel Psychology, vol.15, pp.159-177, 1962.

[9] Smith P C, Kendall L, Hulin C L, The measurement of satisfaction in work and retirement. Chicago Rand McNally, 1969.

[10]Locke, E.A, What is job satisfaction? Organizational Behavior and Human Performance, vol.4, pp.309-336, 1969.

[11] Santhanam G, Jayaraman R, Influence of perceived job satisfaction and its impacts on employee retention in gulf cooperation countries. International Conference on Management Issues in Emerging Economies, pp.218-307, 2012.

[12]Liu caijuan, Study on Factors of Employees' Satisfaction in Commercial Retail Enterprises, Harbin Institute of Technology, 2011. 
[13]Wang wenjun, The Research on Employee Satisfaction and Leaving Tendency of the Enterprise of Different Ownership in Sichuan Province, Southwestern University of Finance and Economics, 2011 .

[14]Zhao liang, Commercial Bank Employee's Satisfaction Factors and Countermeasure Research, East China University of Political Science and Law, 2012.

[15]Xu qin, An Empirical Analysis of the Effect of Knowledge Worker Satisfaction on Job Performance, Statistics \& Decision, vol.5, pp.117-119, 2015.

[16] Gao fuxia, A review of research on employee loyalty in China, China Economist, vol.1, pp. 191-193, 2006.

[17]Jacob KE, Mikkel LN, The managerial drivers of employee satisfaction and loyalty, Total Quality Management, vol.11, pp. 581-588, 2000.

[18] Wang hongmei, Analysis of Factors Affecting Enterprise Employee Loyalty, Contemporary Economics, vol.7, pp. 218-219, 2014.

[19]Liu dexiu, Qin yuanhao, Xu zi, A Psychological Empowerment-Based Study of Employee Loyalty of a Theme Park Hotel, Journal of Southwest University(Natural Science Edition), vol.10, pp. 145-151, 2015.

[20]Zhang xiaomei, An Empirical Study on the Formation Path of Employees Job Satisfaction-Taking Heilongjiang forest industry bureau as an example, Issues of Forestry Economics, vol.32, pp. 98-102, 2016. 